declared, Jose Luis Marenco Speakers bureau: abbie, pfizer, novartis, janmsen

DOI: 10.1136/annrheumdis-2019-eular.6217

\section{AB1174 IS MONITORING SYNOVITIS IN THE HANDS BY ULTRASOUND ENOUGH TO ASSESS TREATMENT EFFECT IN PATIENTS WITH RA IN CLINICAL PRACTICE?}

Dolores Ramos-Bello ${ }^{1}$, Hilde Berner Hammer ${ }^{2}$, Mette Bjørndal Axelsen ${ }^{1}$, Mikkel Ǿstergaard ${ }^{1,3}$, Sin Ngai $\mathrm{Ng}^{4}$, Merete L. Hetland ${ }^{1,3}$, Susanne Juhl Pedersen ${ }^{1}$, Lene Terslev ${ }^{1} .{ }^{1}$ Center for Rheumatology and Spine Diseases, Rigshospitalet, Copenhagen, Denmark; ${ }^{2}$ Diakonhjemmet Hospital, Oslo, Norway, ${ }^{3}$ Department of Clinical Medicine, Faculty of Health Science, Copenhagen University, Copenhagen, Denmark; ${ }^{4}$ Queen Elizabeth Hospital, Medicine department, Hong Kong, China

Background: The use of ultrasound (US) as a tool for assessing disease activity in patients with rheumatoid arthritis (RA) has increased in recent years and its value is supported by studies showing that US provides more accurate assessment of joint inflammation than clinical examination at time of diagnosis and in clinical state of remission.

Various scoring systems have been proposed for monitoring of synovitis. Among these are the novel consensus-based Global OMERACT-EULAR Synovitis Score (GLOESS) was developed applying the highest score of grey-scale (GS) or Doppler as the final score for the joint.

Different joint sets have been proposed for optimal and feasible evaluation of patients with inflammatory arthritis but currently there is no agreement on a specific reduced set of joints that should be evaluated by US to acquire the best information about clinical and subclinical activity when monitoring patients with RA.

Objectives: To evaluate if synovitis assessment of hands only is enough (testing GS, Doppler and GLOESS sum scores) for assessing changes during treatment in order to increase clinical feasibility of US in daily clinical practice.

Methods: US and clinical assessment for tender/swollen joint count (TJC/ SJC) were performed in 19 patients fulfilling ACR 1987 criteria for RA initiating treatment with TNF inhibitor (TNFi) (week 0), and after 6 and 16 weeks of follow up.

Forty-six joints were evaluated by US (sternoclavicular, acromioclavicular, glenohumeral, elbow, wrist, MCP1-5, PIP1-5, hip, knee, ankle and MTP 1-5 bilaterally) using a GE Logiq E9 machine with a linear array transducer. Joint inflammation was graded $0-3$ on GS and Colour Doppler (CD) and synovitis was defined as a GS score $\geq 1$ with or without Doppler score $\geq 1$. Doppler settings for slow flow was applied according to guidelines.

\begin{tabular}{|c|c|c|c|c|c|c|c|c|c|}
\hline & Baseline, & Median & IQR & & Median & IQR & Week 16, rho & & \\
\hline & rho & & & $\begin{array}{l}\text { Weeks, } \\
\text { tho }\end{array}$ & & & & Median & $10 R$ \\
\hline GS 28-joint & 0.94 & 8 & 2-18 & 0.88 & 4 & $1.2-15.7$ & 0.95 & 6 & $1-16.5$ \\
\hline CD 28-joint & 0.94 & 2 & $0-6.5$ & 0.93 & 0 & 0.6 .5 & 0.95 & 0 & $0-4$ \\
\hline 28-GLOESS & 0.93 & 8 & 2-8 & 0.87 & 4 & $1.2-18.5$ & 0.89 & 6 & $1-17.5$ \\
\hline GS hands & 0.90 & 5 & 1-10 & 0.78 & 3 & 1-10.7 & 0.87 & 5 & $0.5-9.5$ \\
\hline $\begin{array}{l}\text { CDhands } \\
\text { chass }\end{array}$ & 0.92 & 1 & ${ }^{0-4}$ & 0.91 & 0 & 0.5 & 0.95 & 5 & $\begin{array}{r}0.3 .5 \\
0.05 .11\end{array}$ \\
\hline Hands GLOESS & 0.88 & $\frac{6}{3}$ & $\frac{1-11}{0.10}$ & 0.78 & 3 & $1-10.7$ & 0.81 & 5 & $\begin{array}{l}0.50-11 \\
0.3\end{array}$ \\
\hline GS 9-joints & 0.51 & 3 & $0-10$ & 0.54 & 0 & 0.4 & 0.30 & 3 & $0-3$ \\
\hline CD 9-joints & 0.81 & 5 & 1-10.2 & 0.73 & 0 & $0-5$ & 0.83 & 5 & $0-9$ \\
\hline 9-GLOESS & 0.95 & 5 & 2-14 & 0.94 & 4 & $1.2-10.5$ & 0.86 & 3 & 0.9 \\
\hline
\end{tabular}

Table

GS, CD and GLOESS sum scores were obtained for the total joint set and different joint subsets: hands as joint set (wrist, 1-5 MCP, 1-5 PIP bilaterally), 28 conventional joints evaluated for DAS and the 9-joint set suggested for the GLOESS (shoulder, elbow, wrist, MCP1 and 4, PIP2, MTP 3 and 5, knee). Data from the different joint sets were analyzed applying Spearman's correlation coefficient.

Results: Mean change in GS sum score between week 0 and 16 was of $2.58,1.35,1.47$ and 1.11 for 46 -joint set, hands, 28-joint set and 9joint set, respectively. Compared to the 46 joint set the GS and CD sums core had a high correlation coefficient $(>0.78)$ for 28 joint set and the hand as joint set for all time points - table 1. The 9 joint set GS sum score had low correlation when compared to the 46 joint set at baseline and during follow up - table 1. GLOESS for the hands performed equally well with a correlation coefficient $(\geq 0.70)$ for all joint sets at all time points - table 1. DAS28-CRP did not correlate with the total joint set or the different joint subsets.

Conclusion: The present study of patients with RA shows that the US examination of both hands only for assessing disease activity is highly correlated for with the 46-joint evaluation at all time points, both regarding GS and Doppler sum scores. Using hands as a reduced joint set US assessment of inflammation could be an option to increase the feasibility of US in routine clinical practice.

Disclosure of Interests: Dolores Ramos-Bello: None declared, Hilde Berner Hammer Grant/research support from: AbbVie, Pfizer and Roche, Paid instructor for: AbbVie, Pfizer, UCB, Novartis, Roche, Speakers bureau: AbbVie, Pfizer, UCB, Novartis, Roche, Mette Bjørndal Axelsen: None declared, Mikkel Ǿstergaard Grant/research support from: Abbvie, Celgene, Centocor, Merck, Novartis, Consultant for: Abbvie, BMS, Boehringer-Ingelheim, Celgene, Eli Lilly, Hospira, Janssen, Merck, Novartis, Novo, Orion, Pfizer, Regeneron, Roche, and UCB, Speakers bureau: Abbvie, BMS, Boehringer-Ingelheim, Celgene, Eli Lilly, Hospira, Janssen, Merck, Novartis, Novo, Orion, Pfizer, Regeneron, Roche, and UCB, Sin Ngai Ng: None declared, Merete L. Hetland Grant/research support from: BMS, MSD, AbbVie, Roche, Novartis, Biogen, Pfizer, Consultant for: Eli Lilly, Speakers bureau: Orion Pharma, Biogen, Pfizer, CellTrion, Merck, Samsung Bioepis, Susanne Juhl Pedersen: None declared, Lene Terslev Speakers bureau: Speakers fee from : Roche, Novartis, Pfizer, MSD, BMS, Celgene

DOI: 10.1136/annrheumdis-2019-eular.6842

\section{AB1175 2 FACET JOINTS INVOLVEMENT IN RHEUMATOID ARTHRITIS: A CROSS-SECTIONAL STUDY}

Tatiana Reitblat ${ }^{1}$, Lina Linov ${ }^{2}$, Fadi Badeer ${ }^{2}$, Azaria Simonovich ${ }^{2}$, Leonid Kalichman ${ }^{3} .{ }^{1}$ Barzilai MC, Rheumatology Unit, Ashkelon, Israel; ${ }^{2}$ Barzilai MC, Radiology, Ashkelon, Israel; ${ }^{3}$ Recanati School for Community Health Professions, Faculty of Health Sciences at Ben-Gurion University of the Negev, Department of Physical Therapy, Beer-Sheva, Israel

Background: Even it is accepted among rheumatologists that rheumatoid arthritis (RA) does not involve the facet joints (FJs) of the spine, the issue is still under debate. Studies that described a prevalence of the FJs in rheumatoid arthritis patients are scarce.

Objectives: To compare the prevalence of FJs changes between patients with RA and age and sex-matched peers.

Methods: We compared computed tomography (CT) scans of 34 patients with RA, who suffered from low back pain, and 70 age and sex-matched controls-people without RA, with low back pain.

The changes in FJs were evaluated according to the score proposed by Kalichman et al: joint space narrowing, marginal osteophytes, articular process hypertrophy, subchondral sclerosis, inter-joint vacuum phenomenon, and subchondral cysts. The characteristic joint changes of RA were also evaluated.

Disease activity characteristics, duration of RA, age, and gender were taken from patients' clinical charts.

Results: Prevalence of facet joints changes in patients with RA and group of age and sex-matched controls were not significantly different at any spinal level or in total L5-S1 score. Marginal erosions, that are characteristic feature of joint change in RA, were not found in any subject with RA in our sample. In subjects with RA, individuals with affected FJs and without affected FJs have no difference in any disease parameters and markers (Tables 1 and 2).

Conclusion: In our samples of CT scans we did not find a difference in facet joints changes between the subject with RA and control group. The occurrence of FJs changes among subjects with RA had no correlation with disease duration and activity. According to the findings, we may assume, that facet joints of the lumbar spine are not involved in the inflammatory process of RA, and patients' low back pain is not due to inflammation in this region of the spine.

Abstract AB1175 Table 1. Prevalence of FJ degenerative changes in patients with RA and age and sex-matched controls.

\begin{tabular}{lccc}
\hline Segment & RA patients & Controls & Comparison $\left(\chi^{2}\right.$-test) \\
\hline L1-L2 Left & $1(3.0 \%)$ & $1(1.8 \%)$ & $\chi^{2}=0.157$, d.f. $=1, p=0.692$ \\
L1-L2 Right & $0(0.0 \%)$ & $0(0.0 \%)$ & - \\
L2-L3 Left & $0(0.0 \%)$ & $1(1.7 \%)$ & $\chi^{2}=0.575$, d.f. $=1, p=0.448$ \\
L2-L3 Right & $1(3.0 \%)$ & $1(1.8 \%)$ & $\chi^{2}=0.157$, d.f. $=1, p=0.692$ \\
L3-L4 Left & $2(6.1 \%)$ & $2(3.4 \%)$ & $\chi^{2}=0.363$, d.f. $=1, p=0.547$ \\
L3-L4 Right & $1(3.0 \%)$ & $4(6.9 \%)$ & $\chi^{2}=0.605$, d.f. $=1, p=0.436$ \\
L4-L5 Left & $2(6.1 \%)$ & $2(3.4 \%)$ & $\chi^{2}=0.342, d . f .=1, p=0.559$ \\
L4-L5 Right & $4(12.1 \%)$ & $3(5.3 \%)$ & $\chi^{2}=1.370$, d.f. $=1, p=0.242$ \\
L5-S1 Left & $4(12.1 \%)$ & $5(8.9 \%)$ & $\chi^{2}=0.233, d . f .=1, p=0.629$ \\
L5-S1 Right & $0(0.0 \%)$ & $5(8.8 \%)$ & $\chi^{2}=3.065$, d.f. $=1, p=0.080$ \\
Total L1-S1 score & $9(27.3 \%)$ & $11(19.0 \%)$ & $\chi^{2}=0.846, d . f .=1, p=0.358$ \\
\hline
\end{tabular}

